\title{
Strategy to prevent epitope masking in CAR.CD19+ B-cell leukemia blasts
}

To cite: Quintarelli C, Guercio M, Manni S, et al. Strategy to prevent epitope masking in CAR CD19+ B-cell leukemia blasts. Journal for ImmunoTherapy of Cancer 2021;9:e001514. doi:10.1136/jitc-2020-001514

\section{- Additional online} supplemental material is published online only. To view, please visit the journal online (http://dx.doi.org/10.1136/jitc2020-001514).

CQ, MG, SM and IB are joint first authors.

Accepted 08 May 2021

Check for updates

(C) Author(s) (or their employer(s)) 2021. Re-use permitted under CC BY-NC. No commercial re-use. See rights and permissions. Published by BMJ.

For numbered affiliations see end of article.

Correspondence to Dr Concetta Quintarelli; concetta.quintarelli@opbg.net

\section{Concetta Quintarelli (D , ${ }^{1,2}$ Marika Guercio, ${ }^{1}$ Simona Manni, ${ }^{1}$ Iolanda Boffa, ${ }^{1}$ Matilde Sinibaldi, ${ }^{1}$ Stefano Di Cecca, ${ }^{1}$ Simona Caruso, ${ }^{1}$ Zeinab Abbaszadeh, ${ }^{1}$ Antonio Camera, ${ }_{1}^{1}$ Biancamaria Cembrola, ${ }^{1}$ Roselia Ciccone, ${ }^{1}$ Alberto Orfao, ${ }^{3}$ Lourdes Martin-Martin, ${ }^{3}$ Sara Gutierrez-Herrero, ${ }^{3}$ Maria Herrero-Garcia, ${ }^{3}$ Gianni Cazzaniga (D) , ${ }^{4}$ Vittorio Nunes, ${ }^{4}$ Simona Songia, ${ }^{4}$ Paolo Marcatili, ${ }^{5}$ Frederikke I Marin, ${ }^{5}$ Marco Ruella (D) , ${ }^{6}$ Valentina Bertaina, ${ }^{1}$ Luciana Vinti, Francesca Del Bufalo (D) , ${ }^{1}$ Mattia Algeri, ${ }^{1}$ Pietro Merli, ${ }^{1}$ Biagio De Angelis, Franco Locatelli ${ }^{1,7}$}

\section{ABSTRACT}

Chimeric antigen receptor T-cells (CAR T-cells) for the treatment of relapsing/refractory B-cell precursor acute lymphoblastic leukemia have led to exciting clinical results. However, CAR T-cell approaches revealed a potential risk of CD19-/CAR+ leukemic relapse due to inadvertent transduction of leukemia cells.

\section{Background}

Methods We evaluated the impact of a high percentage of leukemia blast contamination in patient-derived starting material (SM) on CAR T-cell drug product (DP) manufacturing. In vitro as well as in vivo models were employed to identify characteristics of the construct associated with better profile of safety in case of inadvertent B-cell leukemia transduction during CAR T-cell manufacturing.

Results The presence of large amounts of CD19+ cells in SM did not affect the transduction level of DPs, as well as the CAR T-cell rate of expansion at the end of standard production of 14 days. DPs were deeply characterized by flow cytometry and molecular biology for lg-rearrangements, showing that the level of B-cell contamination in DPs did not correlate with the percentage of CD19+ cells in SM, in the studied patient cohort. Moreover, we investigated whether CAR design may affect the control of CAR+ leukemia cells. We provided evidences that CAR.CD19 short linker (SL) prevents complete epitope masking in CD19+CAR+ leukemia cells and we demonstrated in vitro and in vivo that CD19 +CAR(SL)+leukemic cells are killed by CAR.CD19 T-cells. Conclusions Taken together, these data suggest that a VL-VH SL may result in a safe CAR-T product, even when manufacturing starts from biological materials characterized by heavy contamination of leukemia blasts.

\section{BACKGROUND}

Patient-derived T-cells genetically modified to express chimeric antigen receptors (CARs) specific for CD19 represent an effective treatment for patients with relapsed/ refractory B-cell precursor acute lymphoblastic leukemia (Bcp-ALL). ${ }^{12}$ Indeed, two
Food and Drug Administration approvals (the Novartis' CD19-targeting CAR T-cell product Kymriah and the Kite's product Yescarta, based on a lentiviral and retroviral platform, respectively) have highlighted the rapid pace of progress made in the treatment of B-cell malignancies with CAR T-cells. Given the exciting results reported in patients with CD19+ lymphoid neoplasms receiving CAR T-cells, ${ }^{3}{ }^{4}$ it is expected that a continuously growing number of patients will be offered this treatment and, thus, will be exposed to gene-modified products. Since the techniques of gene manipulation are relatively new, some of the side effects associated with CAR T-cell therapy are still unpredictable and medical researchers, institutions and regulatory agencies are working to ensure that gene therapy is rendered as safe as possible.

In this regard, two Bcp-ALL patients who relapsed with CD19-negative, CAR.CD19expressing leukemia have been reported. This phenomenon was caused by the inadvertent leukemic cell transduction with secondgeneration CAR.CD19 lentivirus during CAR T-cell manufacturing. ${ }^{5}$ Next-generation immunoglobulin (IG) heavy chain sequencing analysis of 17 additional infusion products also identified the leukemic clonotypes in six additional drug products (DPs) (35\% of the total). In vitro and in vivo experiments proved that these CAR+ leukemia cell clones were not killed by CAR.CD19 T-cells, but can be controlled by an anti-CAR.CD19 idiotype CAR. ${ }^{6}$

In this study, we provide evidence that the CAR design may represent a rescue approach in case of CAR.CD19+ leukemic cell generation. 


\section{METHODS}

\section{Cell cultures}

CD19 positive human Burkitt's lymphoma cell lines Daudi, NALM-6 and Raji (American Type Culture Collection Company (USA)) and CD19 negative NonHodgkin's Large Cell Lymphoma cell line Karpas-299 (Sigma Aldrich) were maintained in RPMI 1640 (EuroClone, Italy) supplemented with $10 \%$ heat-inactivated fetal bovine serum (EuroClone), $2 \mathrm{mM}$ l-glutamine (GIBCO, USA), $25 \mathrm{IU} / \mathrm{mL}$ of penicillin, and $25 \mathrm{mg} / \mathrm{mL}$ of streptomycin (EuroClone), in a humidified atmosphere containing $5 \% \mathrm{CO} 2$ at $37^{\circ} \mathrm{C}$. All cell lines were authenticated by PCR-single-locus-technology (Promega, USA. PowerPlex 21 PCR) analysis in 'BMR Genomics s.r.l.' (Italy), and were periodically checked for mycoplasma (VenorGeM Advance, MB Minerva biolabs, UK) and surface markers expression.

\section{Generation and expansion of effector cells}

Buffy coats (BC) from healthy donors (HDs), peripheral blood (PB) and bone marrow (BM) derived from children with Bcp-ALL were used to isolate unfractionated mononuclear cells using Lympholyte Cell Separation Media (Cedarlane, Canada). T-cells were activated with OKT3 $(1 \mu \mathrm{g} / \mathrm{mL}$, ThermoFisher Scientific, USA) and anti-CD28 $(1 \mu \mathrm{g} / \mathrm{mL}$, BD Biosciences, USA) monoclonal antibodies $(\mathrm{mAb})$ with a combination of recombinant human interleukin-7 (rh-IL7, $10 \mathrm{ng} / \mathrm{mL}$; Bio-Techne; USA) and (rh-IL15, $5 \mathrm{ng} / \mathrm{mL}$; Bio-Techne; USA). NK-cells were generated from $\mathrm{BC}$ of HDs following a previously described method. ${ }^{7}$ Then, after $3 / 4$ days, T- and NK-cells were transduced with retroviral supernatant, in 24-well plates precoated with recombinant human RetroNectin (Takara-Bio; Japan). T lymphocytes were expanded in the presence of cytokines, in TexMacs complete medium (Miltenyi, Germany) and replenished twice a week.

\section{CAR constructs}

Four different retroviral CAR constructs were used to carry out the experiments: CAR construct carrying antihuman CD19-scFv from FMC63 clone in which VL and VH fragments were joined by a linker represented by three GSSSS repetitions (3xG4S, long linker, LL), in frame with CD8 stalk domain (short hinge, SH), CD8 transmembrane domain, $4.1 \mathrm{bb}$ and $\mathrm{CD} 3 \zeta$ cytoplasmic domain (CAR.CD19 VL-3GS-VH-CD8-4.1bb.ל, i.e., CAR. CD19 ${ }_{\mathrm{LL} / \mathrm{SH}}$ ); CAR construct carrying anti-human CD19scFv from FMC63 clone in which VL and VH fragments were joined by a linker represented by three GSSSS repetitions (3xG4S, LL), in frame with 16aa sequence derived from human CD34 antigen ( $\triangle$ CD34, long hinge, LH), CD8 stalk domain, CD8 transmembrane domain, $4.1 \mathrm{bb}$ and CD3 $\zeta$ cytoplasmic domain (CAR.CD19 VL-3GS-VH-

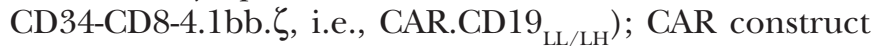
carrying anti-human CD19-scFv from FMC63 clone in which VL and VH fragments were joined by a linker represented by one GSSSS repetition (G4S, short linker, SL), in frame with CD8 stalk domain (SH), CD8 transmembrane domain, 4.1bb and $\mathrm{CD} 3 \zeta$ cytoplasmic domain (CAR.

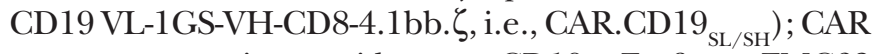
construct carrying anti-human CD19-scFv from FMC63 clone in which VL and VH fragments were joined by a linker represented by one GSSSS repetition (G4S, SL), in frame with 16aa sequence derived from human CD34 antigen $(\triangle \mathrm{CD} 34, \mathrm{LH}), \mathrm{CD} 8$ stalk domain, CD8 transmembrane domain, $4.1 \mathrm{bb}$ and $\mathrm{CD} 3 \zeta$ cytoplasmic domain

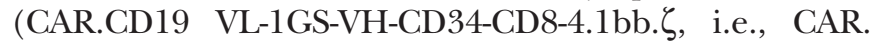
CD19 ${ }_{\mathrm{SL} / \mathrm{LH}}$ ). NALM-6 genetically modified with a lentiviral vector carrying CAR.CD19 already published, ${ }^{5}$ have been kindly provided by Prof. Ruella under a specific material transfer agreement.

T-cells from HDs or Bcp-ALL patients as well as B leukemic cell lines including DAUDI, RAJI and NALM-6 were genetically modified using the retroviral construct CAR.CD19 ${ }_{\mathrm{SL} / \mathrm{LH}}$ or CAR.CD19 ${ }_{\mathrm{LL} / \mathrm{SH}}$. NALM-6 cells were also genetically modified with CAR.CD $19_{\mathrm{LL} / \mathrm{LH}}$ or CAR. CD19 ${ }_{\mathrm{SL} / \mathrm{SH}}$ whereas NK-cells from HDs were genetically modified using only the retroviral construct CAR.CD19 $9_{\mathrm{SL}}$

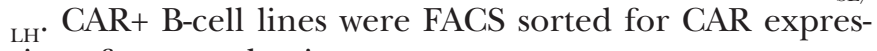
sion after transduction.

\section{Phenotypic analysis}

Fluorescence Activated Cell Sorter (FACS) analysis was performed to determine cell surface antigen expression; $\mathrm{mAb}$ for CD45, CD3, CD19, CD22, CD10, CD34 (all from Becton Dickinson, USA) were combined with different fluorescence according to needs. CAR.CD19 expression was detected using a mAb directed to hCD34 epitope (antiCD34 QBend-10 PE from Bio-Techne, USA), or CD19 CAR Detection Reagent (Biotin; Miltenyi, Germany). Flow cytometry analysis was performed using a BD LSRFortessa X-20 cytometer (BD Biosciences, USA) and analyzed by FACSDiva software (BD Biosciences, USA). FACS sorting of CAR-transduced tumor cell lines was performed on a FACSAria (BD Biosciences, USA). DPs were also characterized by either an 11-color or a 16-color combination of antibodies plus CD19-FITC human protein (anti-CAR TCD19, Cytognos SL, Salamanca, Spain), using the EuroFlow standard operating procedures (SOP) for staining of surface markers only, available at www.EuroFlow.org. ${ }^{8}$ Antibody combinations used were both based on a backbone consisting of the EuroFlow Bcp-ALL MRD tubes previously described for high-sensitive MRD measurements in Bcp-ALL by flow cytometry ${ }^{9-11}$ to which the anti-CD3 and both anti-CD22 and anti-HLADR antibody reagents were added for staining of transfected and non-transfected (NT) T-cells and specific gating of CD19-negative B-cell precursors and blasts, respectively. Finally, the anti-CD34 Qbend10 clone and the CD19FITC human protein (Cytognos SL, Salamanca, Spain) were also added to the reagent staining mix for identification of transfected CAR.CD19 cells. Sample acquisition was performed immediately after sample preparation was completed, and $>1.5 \times 10^{6}$ cells (range: $1.6-7.5 \times 10^{6}$ cells) were measured per sample using an LSRFortessa X-20 flow cytometer and the FACSDiva software or a 3-laser 
Aurora (Cytek Biosciences, California, USA) spectral flow cytometer equipped with the SpectroFlo software (Cytek Biosciences, USA). For instrument setup and data acquisition, the EuroFlow SOP for instrument setup and calibration available at www.euroflow.org was strictly followed. ${ }^{8}$ The Infinicyt software (Cytognos SL, Salamanca, Spain) was used for data analysis.

\section{Quantitative real-time PCR}

Cellular pellets for DNA and RNA extraction were obtained after repeated (three times) and prolonged (10 min at $800 \mathrm{rpm})$ cell washing in PBS $(10 \mathrm{~mL})$, to avoid nucleic acid carry-over from culture. Total RNA was purified with RNeasy Micro Kit (Qiagen, Maryland, USA) according to manufacturer's instructions and reverse transcribed (SuperScript VILO cDNA Synthesis Kit, ThermoFisher Scientific, Italy) in cDNA. Validated assays were considered for TaqMan primers/probes specific for each mRNA analyzed (Hs_00174333 for hCD19, Hs_01060665 for hB-ACTIN, ThermoFisher Scientific). Total DNA was purified by QIAamp DNA Mini Kit (Qiagen) according to the manufacturer's instructions. TaqMan primer/probes were designed for each specific IG or T-cell receptor (TR) clonal target by Primer Express software (Applied Biosystems, Italy). Sequences were reported in online supplemental table 1. Relative gene expression was calculated using the house-keeping gene ACT1N1 (Hs_02249516 ACT1N1, ThermoFisher Scientific, USA). qPCR were performed employing QuantStudio 12K Flex Real-Time PCR System (ThermoFisher Scientific, USA). For IG/ TR PCR-minimal residual disease (MRD) of the DPs, each MRD value was calculated from the corresponding standard curve, and the results were normalized for values of the housekeeping Albumin gene. Quantitative range and sensitive range (SR), positive value, reproducibility of replicates, were interpreted following the Euro MRD guidelines, in order to assign the appropriate MRD value to each sample analyzed, and are reported in Supplemental Table 1 table 1. The reported value of MRD is referred to the value detected at diagnosis of each patients an arbitrary considered equal to 1. qPCR was performed by using the $7900 \mathrm{HT}$ fast-Real Time-PCR System and ViiA7 system (ThermoFisher Scientific, USA) and TaqMan Gene Expression Master Mix (ThermoFisher Scientific, USA).

\section{Allele selection and MHC binding predictions}

We selected all the class I human leukocyte alleles (HLA), as reported from the database allele frequency, found in more than $10 \%$ of the individuals from any of the following datasets: USA NMDP European Caucasian, USA NMDP Middle Eastern or North Coast of Africa, USA NMDP South Asian Indian, USA NMDP Southeast Asian, USA NMDP American Indian South or Central America, USA NMDP African, and USA NMDP Chinese. The HLA alleles selected are: $A * 01: 01, A * 02: 01, A * 03: 01, A * 11: 01$, $A * 23: 01, A * 24: 02, A * 33: 03, B * 07: 02, B * 08: 01, B * 40: 01$, $\mathrm{B} * 46: 01$, and $\mathrm{B} * 53: 01$.
We used the web server NetMHCpan 4.1 to predict HLA binders for all the alleles listed before, for any peptide in the junction regions of the CAR hinge domain plus/ minus 12 residues, with a length between 8 and 12 amino acids. Only peptides that passed the following criteria were further analyzed: (1) The peptide must be predicted as a strong binder for at least one of the alleles; (2) The peptide must be encompassing at least two different regions; (3) Peptides that only have the N-terminal residues before the anchor position from one region, while all the rest is from another region, were discarded.

\section{In vivo CAR+ leukemia mouse model}

Cg-Prkdcscid Il2rgtm1Wjl/SzJ (NSG) female mice were provided by Charles River and maintained in the Plaisant animal facility in Castel Romano, Rome, Italy. All procedures were performed in accordance with the Guidelines for Animal Care and Use of the National Institutes of Health (Ethical committee for animal experimentation Prot. N 088/2016-PR). Tumor growth was monitored weekly by In Vivo Imaging System (IVIS). ${ }^{12}{ }^{13}$ To test CAR T-cell activity on CAR+ leukemia cells, the NSG mouse model was intravenously engrafted with $0.25 \times 10^{6}$ NALM-6 WT or NALM-6 CAR.CD19 ${ }_{\mathrm{SL} / \mathrm{LH}}$ or NALM-6 CAR.CD19 $9_{\mathrm{LL} / \mathrm{SH}}$ or DAUDI CAR.CD19 $9_{\mathrm{SL} / \mathrm{LH}}$ cells genetically modified with firefly luciferase (FF-Luc). On day +3 , mice were treated with $10 \times 10^{6}$ CAR.CD19 T-cells ${ }^{14-18}$ or NT control T-cells. Tumor growth was monitored weekly by IVIS, ${ }^{12}{ }^{13}$ after D-Luciferin (PerkinElmer, USA) intraperitoneal administration.

\section{Statistical analysis}

Unless otherwise noted, data are summarized as mean \pm SD. Student's t-test (two sided) was used to determine statistically significant differences between samples, with a $p<0.05$ indicating a significant difference.

Mouse survival data were analyzed using Kaplan-Meier survival curves and the Fisher's exact test was used to measure statistically significant differences. No valuable samples were excluded from the analyses. Animals were excluded only in the event of death after tumor implant, but before treatment. Neither randomization nor blinding was done during the in vivo study. However, mice were matched based on the tumor signal for control and treatment groups before infusion of control or specific CAR T-cells. To compare the growth of tumors over time, bioluminescence signal intensity was collected in a blind fashion. Bioluminescence signal intensity was log-transformed and, then, compared using a two-sample t-test. We estimated the sample size considering no significant variation within each group of data. We tried to reach a conclusion using a sample size as small as possible. We estimated the sample size to detect a difference in averages of 2 SD at the 0.05 level of significance with an $80 \%$ power. Graphic representations and statistical analysis were performed using GraphPad Prism 6 (GraphPad Software, La Jolla, California, USA). 
A

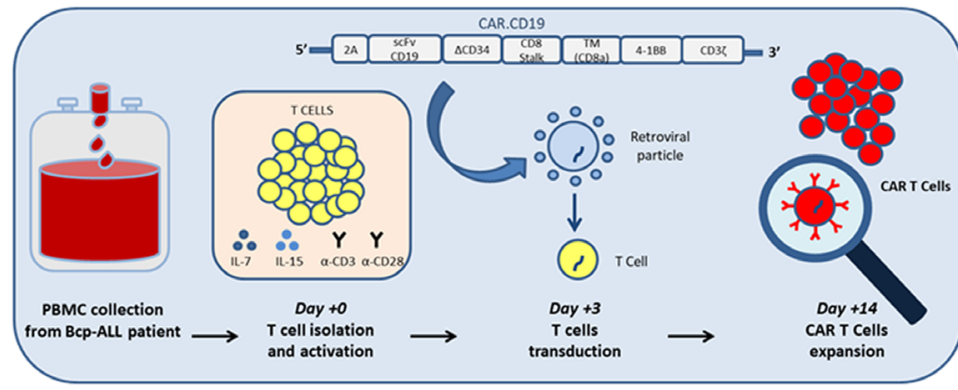

B

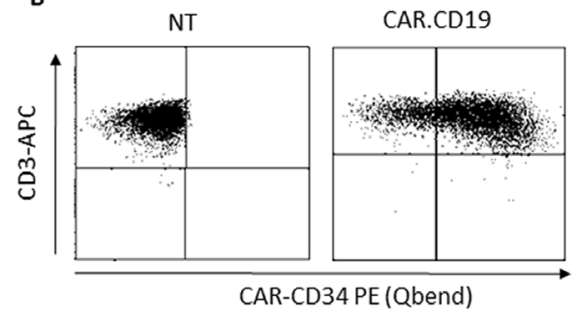

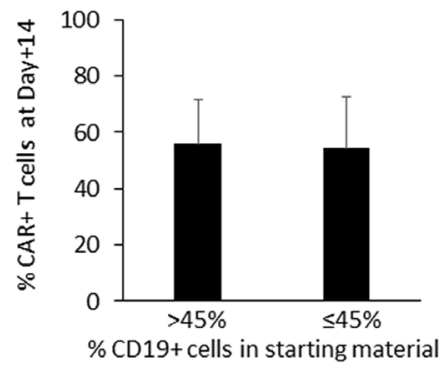

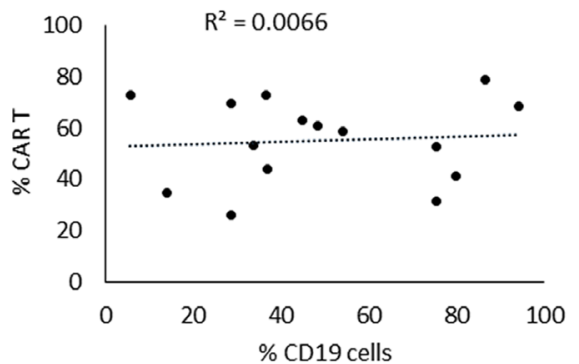

Figure 1 CAR.CD19 T-cells generated from Bcp-ALL patients' derived PBMCs collected at diagnosis. (A) The scFv of $\alpha-C D 19$ is cloned in frame with $\triangle \mathrm{CD} 34$ trackable marker and both 4.1BB and the CD3 $\zeta$ signaling endodomains. PB mononuclear cells of Bcp-ALL patients at diagnosis are activated with $\alpha-\mathrm{hCD} 3 / \alpha-\mathrm{hCD} 28 \mathrm{mAbs}$ and $\mathrm{rh}-\mathrm{IL} 7 / \mathrm{rh}-\mathrm{IL} 15$ and then transduced with the CAR.CD19 $\gamma$-retroviral supernatant. (B) Flow cytometry analysis of a representative donor showing CAR expression by $\triangle$ CD34 detection in untransduced (NT) T-cells (negative control; left panel) and CAR.CD19 genetically modified T-cells (right panel). (C) Percentage of CAR+ T-cells at end-production (day+14) in DPs with more than $45 \%(n=8)$ or equal to/less than $45 \%(n=7)$ of CD19+ leukemia cells in the starting raw material used for CAR T-cell manufacturing. The median value of $45 \%$ was used as cut-off. (D) Correlation matrix between percentage of cCAR+ T-cells in the DPs at the end of production and the percentage of CD19+ leukemic cells in the starting raw materials from patients. (E) Histograms representing the total fold expansion from day+3 to the end of production of CAR T-cells in the two subgroups of patients with $<45 \%$ or $>45 \%$ of CD19+ B-cells in the SM. Bcp-ALL, B-cell precursor acute lymphoblastic leukemia; CAR T, chimeric antigen receptor T-cells' DPs, drug products; mAbs, monoclonal antibodies; SM, starting material; NT, non-transduced.

\section{RESULTS}

\section{Generation of CAR.CD19 T-cells from PB mononuclear cells of} patients affected by Bcp-ALL

Unfractioned PB mononuclear cells isolated from patients at diagnosis had a mean of $45.05 \% \pm 28.12 \%$ contaminating blasts $(\mathrm{n}=15$; range: $5.5 \%-86.4 \%)$. Mononuclear cells derived from $\mathrm{PB}$ of the enrolled patients were transduced with a second-generation CAR. CD19 incorporating an SL between VL/VH and a CD34 16 aa peptide in the hinge region (CAR.CD19 ${ }_{\mathrm{SL}} /{ }_{\mathrm{LH}}$ ), according to the method detailed in figure 1A. At the end of production, T-cell products have shown a CAR transduction efficiency of $55.15 \% \pm 16.54 \%$ (figure 1B shows a representative analysis, whereas figure $1 \mathrm{C}$ shows the average of 15 leukemia patients divided into two groups, based on the percentage of CD19+ cells in the starting material (SM), considering $45 \%$ as cutoff). We sought to evaluate whether leukemia blast contamination in the patients' SM had any impact on the production of CAR T-cells, especially in terms of CAR transduction level in the DPs, as well as on the expansion rate of engineered CAR T-cells. We did not find any correlation between CAR T-cell percentage at the end of the manufacturing procedure and the level of CD19+ B cells contaminating the SM (figure 1C,D). By contrast, the number of T-cells was reduced in the SMs of patients with $>45 \%$ of CD19+ contaminating blasts (day 0, online supplemental figure 1), although the difference with T-cells present in SM with $<45 \%$ of CD19+ cells was not significant due to the small number of analyzed SMs. Irrespectively from the leukemia contamination of the SM, plated T-cells show comparable rate of expansion calculated from day 3 up to the end-production process (figure 1E), allowing to reach similar number of total T-cells in the DP (day 14; online supplemental figure 1). To evaluate patients' samples with an increased percentage of leukemia blast cells, we sought to generate CAR T-cells starting from BM samples of Bcp-ALL patients at diagnosis $(n=10$; online supplemental figure 2) in which the average of CD19+ cells in the BM SM was of $73.1 \% \pm 17.80 \%$ (range: $40.5 \%$ $83.5 \%)$. Although the transduction level in BM-derived 
A

\begin{tabular}{|c|c|c|c|c|}
\hline $\begin{array}{c}\text { ALL } \\
\text { Patients } \\
\text { (PB) }\end{array}$ & $\begin{array}{c}\% \text { CD19+ } \\
\text { Blasts }\end{array}$ & Sample & MRD\#1 & MRD\#2 \\
\hline ALL\#7 & 86,4 & $\begin{array}{c}\text { NT } \\
\text { CAR }\end{array}$ & $\begin{array}{c}1,00 E-04 \\
1,20 E-04\end{array}$ & $\begin{array}{c}\text { NEG } \\
\text { NEG }\end{array}$ \\
\hline ALL\#8 & 28,5 & $\begin{array}{c}\text { NT } \\
\text { CAR }\end{array}$ & $\begin{array}{c}\text { NEG } \\
\text { NEG }\end{array}$ & $\begin{array}{c}\text { ND } \\
\text { ND }\end{array}$ \\
\hline ALL\#9 & 5,5 & $\begin{array}{c}\text { NT } \\
\text { CAR }\end{array}$ & $\begin{array}{c}\text { NEG } \\
\text { NEG }\end{array}$ & NEG \\
\hline ALL\#4 & 28,7 & $\begin{array}{c}\text { NT } \\
\text { CAR }\end{array}$ & $\begin{array}{c}\text { ND } \\
\text { NEG }\end{array}$ & $\begin{array}{c}\text { ND } \\
\text { NEG }\end{array}$ \\
\hline ALL\#10 & 44,8 & $\begin{array}{c}\text { NT } \\
\text { CAR }\end{array}$ & $\begin{array}{c}9,40 E-03 \\
8,40 E-03\end{array}$ & $\begin{array}{c}2,30 E-03 \\
1,90 E-03\end{array}$ \\
\hline ALL\#6 & 75,3 & $\begin{array}{c}\text { NT } \\
\text { CAR }\end{array}$ & $\begin{array}{c}\text { NEG } \\
\text { NEG }\end{array}$ & $\begin{array}{c}\text { NEG } \\
\text { NEG }\end{array}$ \\
\hline ALL\#11 & 13,9 & $\begin{array}{c}\text { NT } \\
\text { CAR }\end{array}$ & $\begin{array}{c}1,10 E-03 \\
\text { NEG }\end{array}$ & $\begin{array}{c}6,00 E-04 \\
\text { NEG }\end{array}$ \\
\hline ALL\#12 & 79,8 & $\begin{array}{c}\text { NT } \\
\text { CAR }\end{array}$ & $\begin{array}{c}1,50 E-04 \\
3,50 E-04\end{array}$ & $\begin{array}{c}1,00 E-04 \\
1,30 E-04\end{array}$ \\
\hline ALL\#13 & 33,6 & $\begin{array}{c}\text { NT } \\
\text { CAR }\end{array}$ & $\begin{array}{c}\text { NEG } \\
\text { NEG }\end{array}$ & $\begin{array}{c}\text { NEG } \\
\text { ND }\end{array}$ \\
\hline ALL\#14 & 36,8 & $\begin{array}{c}\text { NT } \\
\text { CAR }\end{array}$ & $\begin{array}{c}1.2 E-04 \\
\text { NEG }\end{array}$ & $\begin{array}{c}\text { NEG } \\
\text { NEG }\end{array}$ \\
\hline ALL\#15 & 48.3 & $\begin{array}{c}\text { NT } \\
\text { CAR }\end{array}$ & $\begin{array}{c}1.9 E-04 \\
6.4 E-04\end{array}$ & $\begin{array}{c}\text { ND } \\
\text { ND }\end{array}$ \\
\hline ALL\#16 & 75.2 & $\begin{array}{c}\text { NT } \\
\text { CAR }\end{array}$ & $\begin{array}{c}3.4 E-03 \\
2.7 E-03\end{array}$ & $\begin{array}{c}3.5 E-03 \\
2.1 E-02\end{array}$ \\
\hline ALL\#18 & 36.4 & $\begin{array}{c}\text { NT } \\
\text { CAR }\end{array}$ & $\begin{array}{c}3.4 E-04 \\
3.0 E-04\end{array}$ & $\begin{array}{c}6.2 E-04 \\
\text { NEG }\end{array}$ \\
\hline ALL\#19 & 94.1 & $\begin{array}{c}\text { NT } \\
\text { CAR }\end{array}$ & $\begin{array}{c}3.8 E-03 \\
2.1 E-03\end{array}$ & $\begin{array}{c}\text { ND } \\
\text { ND }\end{array}$ \\
\hline
\end{tabular}

B

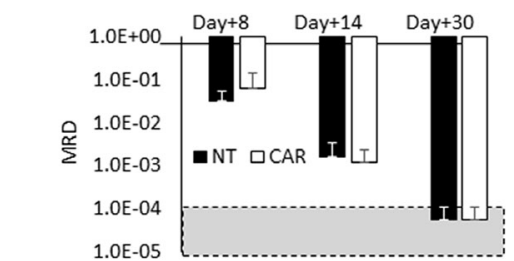

C
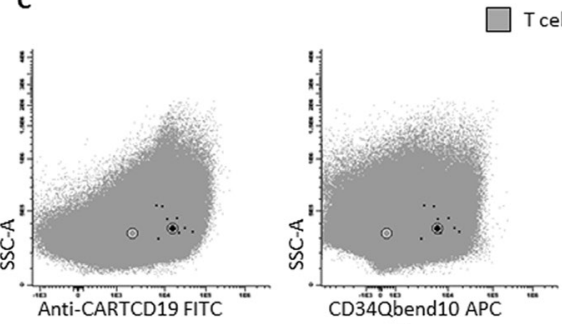

T cells

B-cell precursors
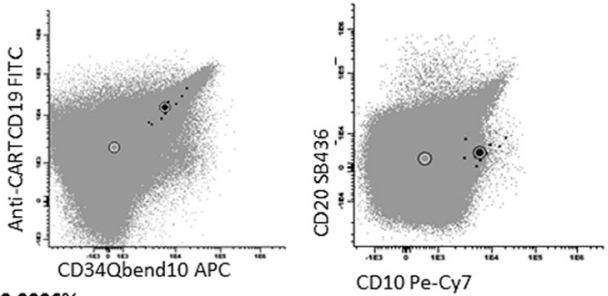

ALL\#12 9 B-cell precursors in $1.5 \times 10^{6}$ alive cells: MRD $0.0006 \%$
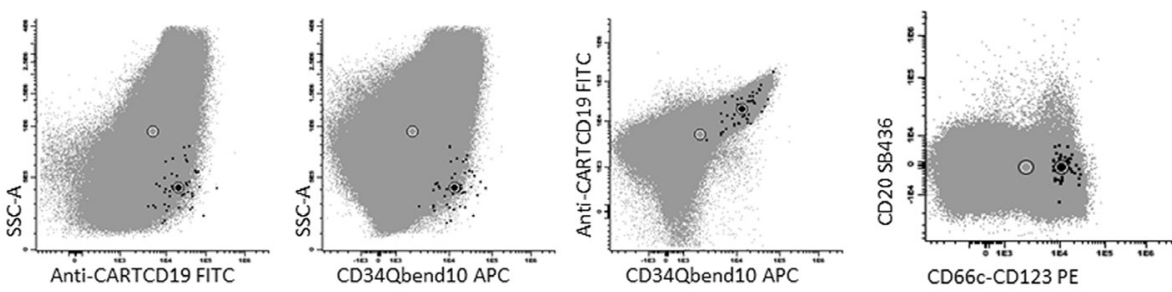

ALL\#14 36 B-cell precursors in 1 × $10^{6}$ alive cells: MRD 0.0036\%

Figure 2 MRD analysis in DPs generated from raw materials of Bcp-ALL patients highly contaminated by leukemia cells at diagnosis. (A) The table shows data for each enrolled patient as regards to the percentage of CD19+ leukemia cells (MRD=1) in the PBMC used as starting raw material for CAR T-cell manufacturing, and the value of MRD for two different IG markers identified at diagnosis in each single patient. MRD data were reported for both control untransduced T-cell samples (NT) and CAR.CD19 T-cell samples (CAR). (B) time-course experiments have been designed to evaluate the impact of manufacturing time on MRD value in DPs. T-cells were generated from five different patients $(n=5)$ and cultured for 8,14 or 30 days before collection of the cells for MRD analysis, performed by qPCR analysis on IG rearrangement with detection limit specified in online supplemental table 1 , and represented in the figure as negative range between $10^{-4}$ and $10^{-5}$ (dotted gray area). (C) Flow cytometry analysis of two DPs: ALL\#12 with high MRD values and ALL\#14 for which the detection of MRD was below the PCR sensitivity. Panels show the presence of leukemia cells (black dots) positive for CAR expression, detected with both anti-CAR. CD19 FITC antibody (anti-CARTCD19, Cytognos SL, Salamanca, Spain) and anti-CD34 APC (CD34QBEND10), targeting the CD34 epitope in the CAR construct. Bcp-ALL, B-cell precursor acute lymphoblastic leukemia; CAR, chimeric antigen receptor; DPs, drug products; NT, non-transduced.

samples was significantly lower than in PB-samples (online supplemental figure 2A,B; $36.04 \pm 19.83 \%$ vs $55.15 \pm 16.54 \%$ CAR + T-cells, respectively; $\mathrm{p}=0.03)$, also in this case we did not observe any difference in terms of total yield from $\mathrm{PB}$ or BM samples (online supplemental figure 2C).

\section{Deep characterization of patient-derived CAR T-cell products}

We performed real-time quantitative PCR on CAR T-cell DPs (day+14, end of production) for the amplification of leukemia-specific IG rearrangements. We observed positivity of MRD in 7/14 tested CAR T-cell DPs, with a median MRD value of 6.01E-3 $\pm 1.00 \mathrm{E}-2$ (CAR, figure 2A). Moreover, we observed that leukemic blast contamination was present in 9/13 untransduced T-cell samples tested (NT, figure $2 \mathrm{~A}$ ) with a median value of $1.57 \mathrm{E}-3 \pm 1.86 \mathrm{E}-3$. These results suggest that leukemic cells, although at minimal levels, may survive during CAR T-cell manufacturing for 14 days. In addition, to understand the dynamics of BcpALL cell survival during manufacturing, we performed time-course experiments in which DPs were analyzed for MRD at a very early time point as of day +8 after activation, day +14 as standard procedures for CAR T-cell manufacturing, and day+30 as the most extended culture period for a CAR T-cell DPs (data from five different patients' production). As shown in figure 2B, we observed an inverse correlation between MRD levels and time in culture, $(p=0.02$ considering MRD at day $+8 v$ s day +14$)$, reaching at the last time point $($ day +30$)$ a value beyond the sensitivity level of the used method (online supplemental table 1 specify sensitivity range for each patient's assay; SR $10^{-4}-10^{-5}$ ). For those samples with enough available leftover material, we performed high-sensitivity EuroFlow flow cytometry analysis ${ }^{19}$ to better characterize Bcp-ALL cells contaminating the DPs. As shown in online supplemental figure 3, the applied flow cytometry test was sensitive enough to detect positive MRD in CAR T-cell DP at day+14. B-cell precursors contaminating CAR products resulted to be CD19 dim (online supplemental 
figure 3), although maintained other B-cell markers like CD10. On the contrary, the B-cells contaminating NT T-cells remained CD19+ and were significantly higher in number than those observed in CAR samples (online supplemental figure $3, \mathrm{CD} 19+\mathrm{MRD}$ of $1.5 \%$ vs $0.00036 \%$, respectively). We then sought to verify whether B-cells were characterized by the presence of CAR transduction. As shown in figure $2 \mathrm{C}$, for two samples analyzed by flow cytometry, we detected CAR+ leukemia cells showing double positivity for two different CAR-associated markers (anti-CD34, detecting the epitope on the hinge region of CAR.CD19 $_{\mathrm{SL} / \mathrm{LH}}$ as well as CD19 epitope recognized by CAR.CD19 scFv), although the number of detected CAR+ B-cells was at the limit of detection for ALL\#12.

MRD data were also confirmed on BM-derived DPs, in which RT-qPCR showed MRD positivity in 6/6 CAR T-cell products (online supplemental figure 4A). For two BM-derived DPs, MRD positivity was also confirmed by the EuroFlow flow cytometry assay (online supplemental figure 4B). In BM-derived DPs, the sensitivity of the assay and the quality of frozen samples did not allow detection of CAR positive B-cell precursors. Moreover, in BM-derived CAR T-cell products, B-cell precursors contaminating the DPs were CD19 dim/negative, whereas untransduced T-cells have shown contaminating B-cells with high expression of CD19 (online supplemental figure 4B).

\section{The length of the CAR linker influences epitope masking}

We sought to evaluate whether CAR.CD19 design in the linker and the hinge regions could have any impact on the CD19 masking when CAR.CD19 is coexpressed with CD19 on the same cellular membrane of tumor cells (in cis expression). In particular, we considered two CAR configurations with a relevant clinical interest. The first CAR is characterized by a standard configuration of LL between VL and VH derived from FMC63 clone, and a $\mathrm{SH}$ before the $\mathrm{CD} 8$ transmembrane domain represented by CD8 stalk (CAR.CD19 ${ }_{\mathrm{LL} / \mathrm{SH}}$ ) (figure 3A, construct a). ${ }^{20}$ The second one, is represented by the CAR construct used in the current clinical trial NCT03373071 (at 'Bambino Gesù Children Hospital', Rome, Italy), in which the SL between VL and VH regions, is associated to the LH that includes $\triangle \mathrm{CD} 34$, as trackable marker for CAR T-cells, placed before the CD8 stalk (CAR.CD19 ${ }_{\mathrm{SL} /}$ ${ }_{\mathrm{LH}}$ ) (figure 3A, construct $\mathrm{b}$ ). After transduction with the two constructs, CAR+ NALM-6 maintained CD19 positivity at the mRNA level (online supplemental figure 5A). Nevertheless, the pattern of CD19 fluorescence detected by flow cytometry in CAR.CD19 $9_{\mathrm{LL} / \mathrm{SH}}$ NALM- 6 and CAR. CD19 ${ }_{\mathrm{SL} / \mathrm{LH}}$ NALM-6 was reduced compared with CD19 expression in NALM-6 WT, tested either with the FMC63 (figure 3B) or HIB19 clone (figure 3C), confirming previously published data (online supplemental figure 6A
A

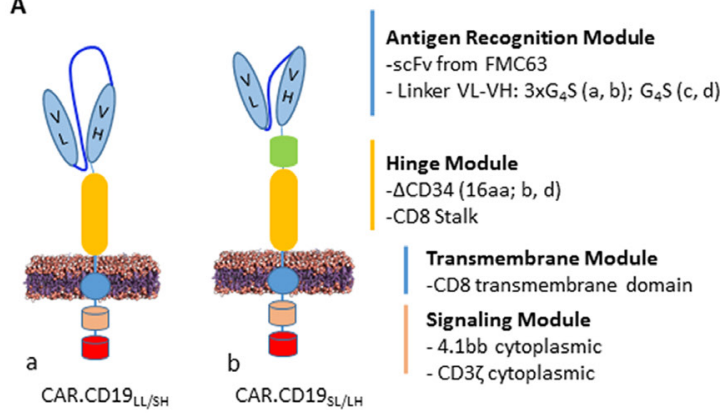

CAR.CD19 $9_{\text {SL/LH }}$
B

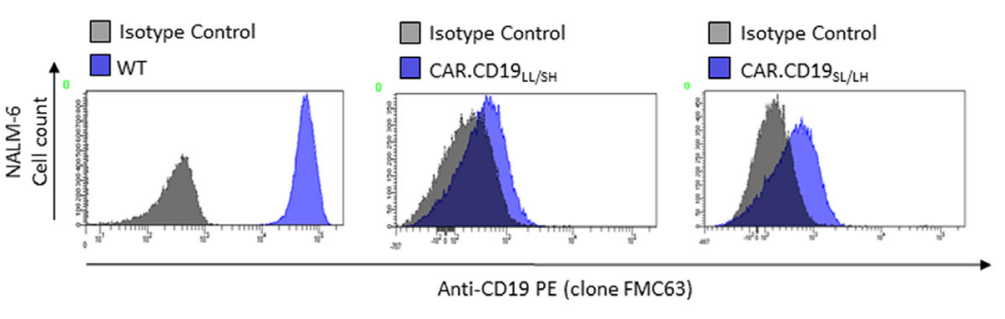

C

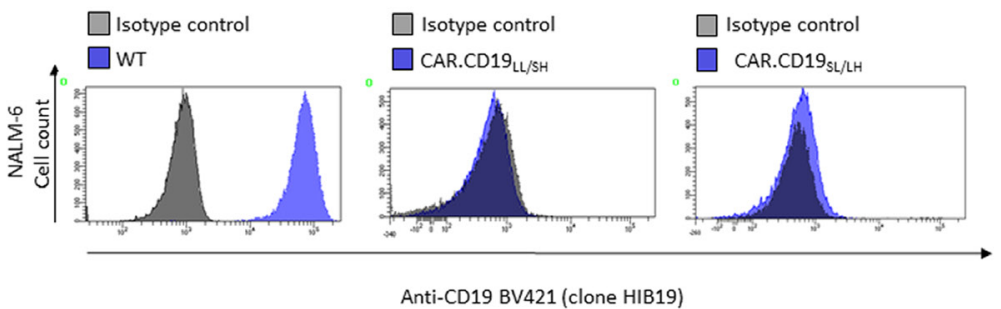

Figure 3 CAR.CD19 structure affects CD19 antigen engagement when both CD19 antigen and CAR.CD19 are expressed on the same plasma membrane. (A) Cartoons representing CAR.CD19 ${ }_{L L S H}$ (a), and CAR.CD19 ${ }_{S L / L H}$ (b). (B, C) CD19 expression detected by flow cytometry in NALM- 6 cells genetically modified by different CAR.CD19 constructs. Matched isotype staining is shown by gray histograms, whereas CD19 staining with anti-CD19 PE (clone FMC63) (B) or anti-CD19 BV421 (clone HIB19) (C) is shown by blue histograms for each CAR.CD19 modified NALM-6 cell lines. CAR, chimeric antigen receptor; WT, wild-type. 
shows the masking experiments on NALM-6 genetically modified with a lentiviral construct expressing a CAR. CD19 ${ }_{\text {LL/SH, }}$ kindly provided by prof. Ruella). ${ }^{5}$ Notably, CAR.CD19 $_{\text {LL/SH }}$ NALM-6 cells showed lower CD19 Mean Fluorescent Intensity (MFI) than CAR.CD19 $9_{\mathrm{SL} / \mathrm{LH}}$ NALM-6 (figure 3B,C), suggesting a lower CD19 masking in this last CAR+ cell line. The uncomplete CD19 masking was also confirmed in DAUDI and RAJI cell lines transduced with CAR.CD19 $9_{\mathrm{SL} / \mathrm{LH}}$ (online supplemental figure 7, clone HIB19). To demonstrate which variable (linker or hinge) in CAR construct is responsible in regulating CD19 antigen masking in CAR+ leukemia cells, we proceeded considering other two different second-generation CAR. CD19 configurations in a retroviral platform (online supplemental figure 8A): one with LL and LH (CAR. CD19 ${ }_{\mathrm{LL} / \mathrm{LH}}$ ), (online supplemental figure $8 \mathrm{~A}$, construct a) and the second one, with SL and SH (CAR.CD19 ${ }_{\mathrm{SL} /}$ ${ }_{\mathrm{SH}}$ ), (online supplemental figure $8 \mathrm{~A}$, construct b). Also in this case, masking flow cytometry analysis showed that CD19 MFI was significantly higher in NALM-6 expressing an SL (CAR.CD19 ${ }_{\mathrm{SL} / \mathrm{SH}}$ NALM-6) than the same cell line expressing the CAR with the configuration of LL (CAR.CD19 ${ }_{\mathrm{LL} / \mathrm{LH}}$ NALM-6; online supplemental figure 8B for FMC63 clone and online supplemental figure 8C for clone HIB19). Based on these observations, the linker length could be the factor driving a complete or uncomplete antigen masking when CAR.CD19 is coexpressed in cis with CD19 on CAR+ leukemia cells. These data were also corroborated by functional analysis. Indeed, very low level of CD19 expression on DAUDI, RAJI and NALM-6 CAR.CD19 ${ }_{\mathrm{SL} / \mathrm{LH}}$ cells was sufficient to elicit CAR.CD19 T-cell response, (figure 4A-E). In particular, CAR.CD19 T-cells exert a significant leukemia control against NALM-6 WT, with no significant differences compared with the anti-leukemia activity observed

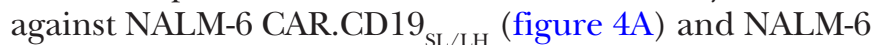
CAR.CD19 $9_{\text {SL/SH }}$ (online supplemental figure 8D). Notably, whereas CAR.CD19 T-cells were completely unable to recognize NALM-6 CAR.CD19 ${ }_{\mathrm{LL} / \mathrm{SH}}$ in the lentiviral platform (online supplemental figure $6 \mathrm{~B}$ ) as reported in the previous publication, ${ }^{5}$ we observed some activity of CAR. CD19 T-cells against NALM-6 CAR.CD19 ${ }_{\mathrm{LL} / \mathrm{SH}}$, although to a lower extent compared with NALM-6 CAR.CD19 ${ }_{\mathrm{SL} / \mathrm{LH}}$ (figure 4A) and NALM-6 CAR.CD19 ${ }_{\mathrm{SL} / \mathrm{SH}}$ (online supplemental figure $8 \mathrm{D}$ ). In line with these findings, we also observed that NALM- 6 cells genetically modified with both CAR.CD19 with SL or LL were able to induce a significant amount of interferon-gamma (IFN $\gamma$ ) by CAR T-cells (online supplemental figures $9 \mathrm{~A}$ and $8 \mathrm{E}$ ), as well as to induce their proliferation (online supplemental figure 9B). Moreover, NALM-6 CAR.CD19 ${ }_{\mathrm{LL} / \mathrm{SH}}$ induced a lower CAR.CD19 T-cell proliferation compared with WT

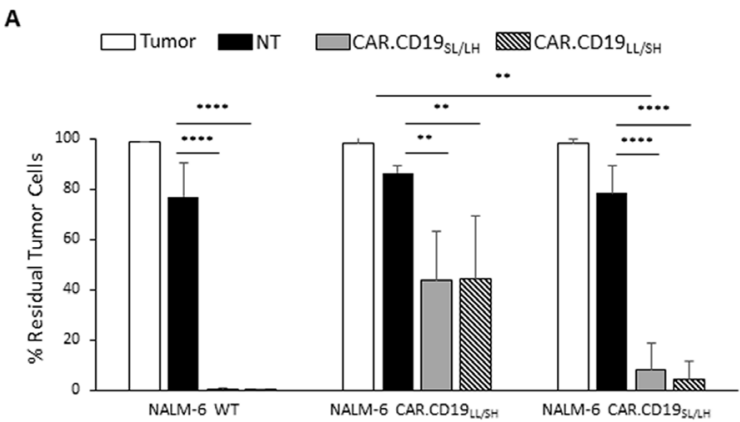

B

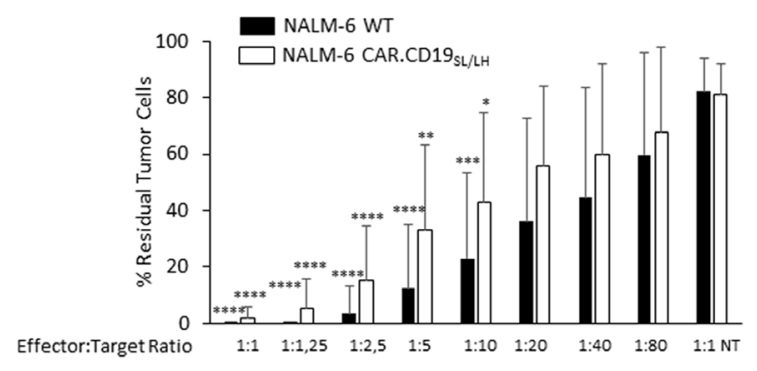

c

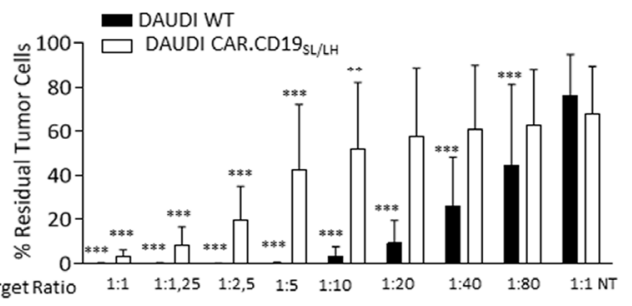

D

Figure 4 Long-term in vitro assays to evaluate the activity of CAR.CD19 T-cells. (A) 7 days coculture assay ( $\mathrm{n}=6$ ) of WT and CAR +NALM-6 alone (white bars), with nt (black bars), CAR.CD19 ${ }_{\mathrm{SL} / \mathrm{LH}}$ (gray bars) and CAR.CD19 ${ }_{\mathrm{LL} / \mathrm{SH}}$ (dotted bars) T-cells. (B-D) 7 days co-culture assays of WT and CAR.CD19 ${ }_{\mathrm{SL} / L \mathrm{H}}$ NALM-6 $(B, n=10)$, Daudi $(C, n=5)$ and Raji $(D, n=5)$ with CAR.CD19 ${ }_{\text {SLLLH }}$ Tcells were performed at decreasing effector:target ratios (E/T), from 1:1 to 1:80. (E) 7 days coculture assays ( $n=5)$ of NALM-6 WT with CAR.CD19 ${ }_{\mathrm{SL} / \mathrm{LH}}$ (black bars) or CAR.CD19 ${ }_{\mathrm{LL} / \mathrm{SH}}$ (gray bars) T-cells were performed at decreasing E/T, from 1:1 to 1:80. Data are expressed as mean $\pm S D$. ${ }^{*} \mathrm{P} \leq 0.05,{ }^{* \star} \mathrm{p} \leq 0.01,{ }^{\star \star \star} \mathrm{p} \leq 0.001,{ }^{\star \star \star \star} \mathrm{p} \leq 0.0001$. CAR, chimeric antigen receptor; $\mathrm{T}$, non-transduced; WT, wild-type. 
and CAR.CD19 $9_{\mathrm{SL} / \mathrm{LH}}$ NALM-6 cells (see P2 gates, online supplemental figure 9B).

\section{SL and LH in CAR.CD19 construct did not affect CAR functionality and immunogenicity}

Notably, whereas CAR.CD19 $9_{\mathrm{SL} / \mathrm{LH}}$ is leading to the uncomplete $\mathrm{CD} 19$ antigen in cis masking, when expressed in T-cells it was able to exert a significant leukemia/lymphoma control. In particular, coculture assay was used to demonstrate the cytotoxic effect of CAR.CD19 ${ }_{\mathrm{SL} / \mathrm{LH}}$ T-cells against NALM-6 (figure 4A,B), DAUDI (figure 4C) and RAJI (figure 4D) cell lines. As shown in figure $4 \mathrm{~B}-\mathrm{D}$, CAR.CD $19_{\mathrm{SL} / \mathrm{LH}} \mathrm{T}$-cells are able to significantly eliminate tumor cells from the culture even when used at low effector/target ratio. For the NALM-6 model, we have also compared the anti-lymphoma activity of CAR.CD19 $9_{\mathrm{SL} / \mathrm{LH}}$ T-cells with that of the more standard CAR.CD19 ${ }_{\mathrm{LL} / \mathrm{SH}} \mathrm{T}$-cells, not revealing substantial differences in terms of cytotoxicity (figure 4E, NALM-6 WT), IFN $\gamma$ production (online supplemental figure 9A), or proliferation index after antigen stimulation (online supplemental figure 9B). This last assay was performed by stimulating CFSE loaded CAR T-cells with NALM-6 WT, and observing that irrespectively of the CAR construct, both CAR.CD19 T-cells were able to reach comparable level of proliferating cells (light gray histograms) compared with unstimulated cells (dark gray histograms). Moreover, since we have included in the LH CAR configuration the trackable marker CD34, we have also performed in silico analysis to predict its immunogenicity. In particular, we have studied the peptide sequences that are confidently foreseen to be presented by HLA molecules in the CAR region that include CD34 domain. 'STNVSPAPR' peptide is predicted as potentially immunogenic for CD34-including construct (online supplemental table 2), presented by the molecules HLA-A11:01 and HLAA33:03. The peptide 'GSELPTQGTF' also matches the selection criteria, but in this case, its binding core is 'ELPTQGTF' and is entirely part of the CD34 epitope region, therefore unlikely to be highly immunogenic. For the CAR construct in which CD34 domain was not considered, the peptides 'SVTVSSPAPR' and its shorter version 'SVTVSSPAPR' are both predicted to be immunogenic, presented by the same alleles HLA-A11:01 and HLA-A33:03. In light of this finding, we predict that the inclusion of CD34 domain in the construct did not substantially affect the immunogenic profile of the CAR.

\section{In vivo models for evaluation of CAR.CD19 T-cell activity against CAR+ leukemia cells}

The ability of CAR.CD19 T-cells to target wild-type B-cell lymphoma beside CAR construct with an SL or a LL has been proved in vivo in a B-cell lymphoma NSG xenograft model. In particular, mice were infused systemically with NALM-6 genetically modified with FF-Luc to allow in vivo monitoring of the leukemia burden overtime. Tumor engraftment was analyzed by measuring the bioluminescence signal, and, on day +0 , mice were treated with either CAR.CD19 ${ }_{\mathrm{SL} / \mathrm{LH}}$ or CAR. CD19 ${ }_{\mathrm{LL} / \mathrm{SH}}$ T-cells as well as with NT untransduced control T-cells (NT) derived from HDs (figure 5A-C). CAR.CD19 $9_{\mathrm{SL} / \mathrm{LH}}$ and CAR.CD19 ${ }_{\mathrm{LL} / \mathrm{SH}}$ T-cells were able to significantly control NALM-6 in vivo expansion, as clearly demonstrated by bioluminescence analysis. We then sought to evaluate whether NALM-6 CAR.CD19 $9_{\mathrm{SL}}$ ${ }_{\mathrm{LH}}$ were also recognized by CAR T-cells in the in vivo setting. As shown in figure 5D-F, CAR.CD19 ${ }_{\text {SL/LH }}$ T-cells were able to reduce significantly CAR+ NALM-6 cell in vivo expansion compared with NT. The same data were also confirmed in a less aggressive lymphoma model of DAUDI cell line (figure 6A). In this model, CAR.CD19 $9_{\mathrm{SL} / \mathrm{LH}}$ T-cells were able to control and eliminate CAR+ leukemia in all treated mice (figure 6B shows bioluminescence overtime for five mice/cohort, whereas bioluminescence averages were reported in figure 6C). The mouse cohort treated with CAR.CD19 T-cells reached $100 \%$ disease-free survival (DFS) at the end of the experimental procedure $($ day+21) vs $0 \%$ DFS for the control cohort of mice receiving NT T-cells. Moreover, we also corroborate the in vitro data relative to NALM-6 CAR.CD19 ${ }_{\mathrm{LL} / \mathrm{SH}}$. Also in the in vivo setting, CAR T-cells were able to exert antileukemia control against NALM-6 CAR.CD19 ${ }_{\mathrm{LL} / \mathrm{SH}}$ (figure 5G-I), although to a lower extent of those observed in CAR. CD19 ${ }_{\text {SL/LH }}$ model (figure 5D-F and online supplemental figure 10).

\section{DISCUSSION}

Pivotal CAR T-cell clinical trials involving patients with Bcp-ALL or large B-cell lymphoma have revolutionized anticancer therapy. ${ }^{21-23}$ However, growing experience with these agents has highlighted challenges associated with the manufacturing of patient-derived DPs. As more patients are treated and longer follow-up data are becoming available, it is clear that approximately $30 \%-50 \%$ of the patients who achieved first remission with CAR.CD19 T-cells will have a relapse, within 1 year of treatment. ${ }^{3424}$ Loss or downregulation of the target antigen $^{25-27}$ and /or a lack of CAR T-cell persistence, ${ }^{28-30}$ as well as product manufacturing failures, are counted among the most frequent causes of CAR T-cell therapy limitations. ${ }^{2431} 32$

Understanding and overcoming these hurdles will be crucial to increase the potential of this novel treatment, particularly when the approach will be extended to other indications, including solid tumors. Herein, we first provide evidence that the use of patient-derived material, highly enriched in Bcp-ALL cells from patients at diagnosis, results in the generation of CAR T-cell products with equal T-cell expansion rate compared with DPs generated from HDs or patients with lower leukemia cell contamination. We also sought to evaluate whether the percentage of B-cells in the SM could correlate with 
A

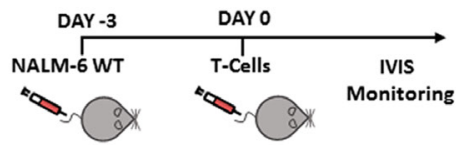

B

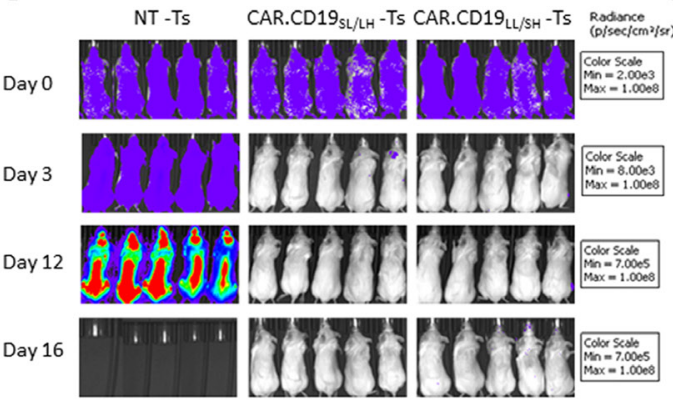

C

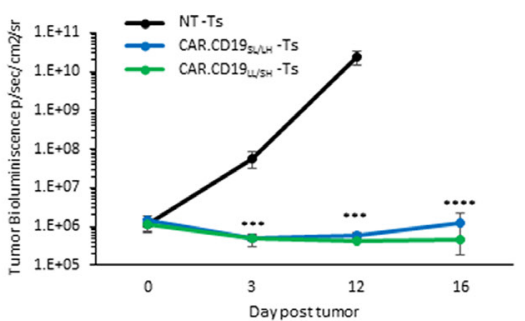

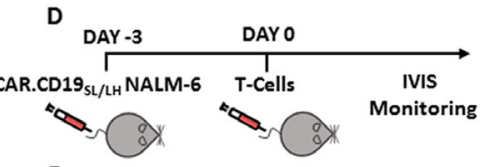

E
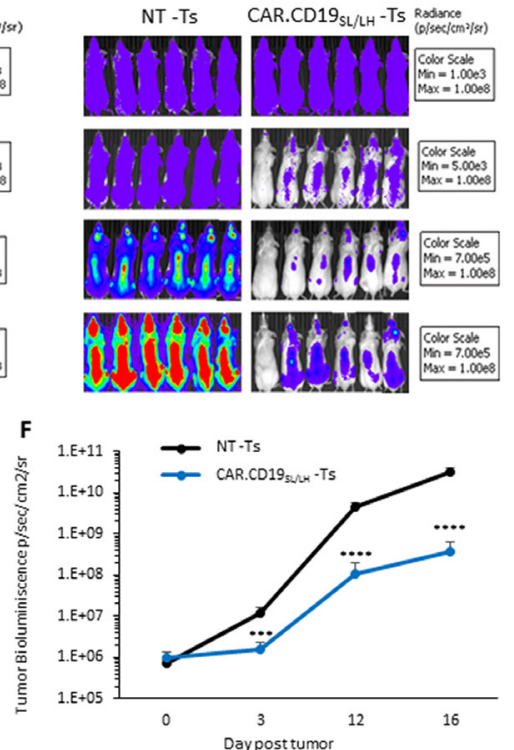
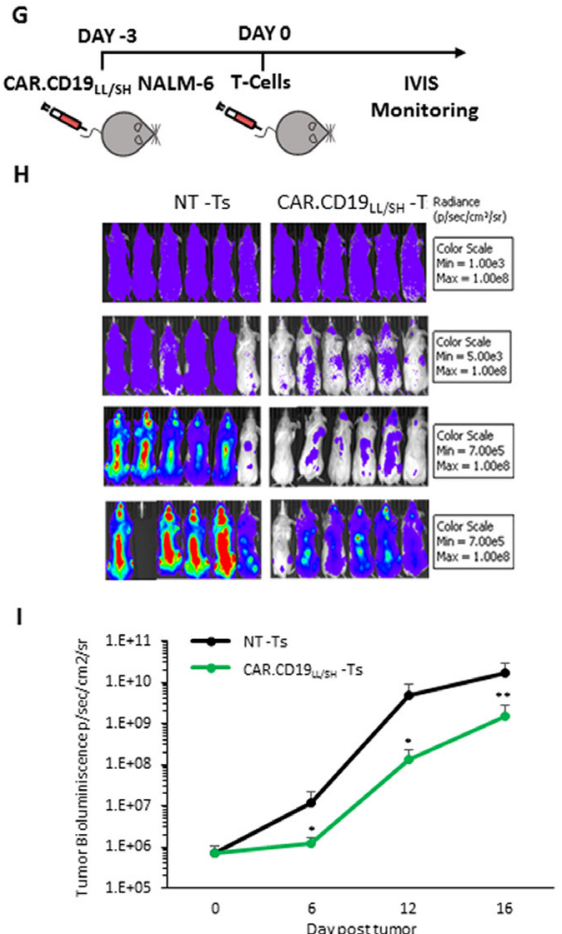

Figure 5 T-cells genetically modified with different CAR.CD19 constructs are differently able to control in vivo expansion of CAR+ leukemia in a xenograft mouse model. (A-C) Schematic representation of the experimental design, with FF-Luc positive NALM-6 WT cells, infused at day-3. At day 0, mice were evaluated for leukemia engraftment and treated with $10 \times 10^{6}$ untransduced (NT) or CAR.CD19 ${ }_{\text {SLLL }}$ or CAR.CD19 ${ }_{\text {LUSH }}$ T-cells/mouse (A). Bioluminescence imaging of each treated mouse (B). Mean \pm SD of bioluminescence values of the three mice cohorts, receiving NT (black line) or CAR.CD19 ${ }_{\mathrm{SL} L \mathrm{H}}$ T-cells (blue line) or CAR.CD19 ${ }_{\mathrm{LLSH}}$ T-cells (green line) (C). (D-F) Schematic representation of the experimental design, with CAR.CD19 ${ }_{\mathrm{SL}}$ ${ }_{1 H}$ positive/FF-Luc positive NALM-6 cells, infused at day -3 . At day 0 , mice were evaluated for leukemia engraftment and treated with $10 \times 10^{6}$ untransduced (NT) or CAR.CD19 $9_{\mathrm{SLIH}}$ (D). Bioluminescence imaging of each treated mouse (E). Mean \pm SD of bioluminescence values of the two mice cohorts, receiving NT (black line) or CAR.CD19 ${ }_{\text {SLLL }}$ T-cells (blue line) (F). (G-I) Schematic representation of the experimental design, with CAR.CD19 ${ }_{\text {LUSH }}$ positive/FF-Luciferase positive NALM-6 cells, infused at day-3. At day 0 , mice were evaluated for leukemia engraftment and treated with $10 \times 10^{6}$ untransduced (NT) or CAR.CD19 ${ }_{\text {LLSH }}$ (G). Bioluminescence imaging of each treated mouse $(\mathrm{H})$. Mean $\pm \mathrm{SD}$ of bioluminescence values of the two mice cohorts, receiving NT (black line) or CAR.CD19 ${ }_{\text {s }}$ T-cells (green line) (I). ${ }^{*} \leq 0.05,{ }^{* *} \mathrm{p} \leq 0.01,{ }^{* * *} \mathrm{p} \leq 0.001,{ }^{* * * *} \mathrm{p} \leq 0.0001$. CAR, chimeric antigen receptor; FF, firefly; LL, long linker; NT, non-transduced; SH, short hinge; WT, wild-type.

leukemia cell contamination in DPs, but we did not find any correlation.

Ruella $e t a \tilde{l}$ reported the presence of leukemic clonotypes in patient-derived DPs obtained through gene manipulation based on a lentiviral vector encoding for a second-generation CAR.CD19. In detail, these authors described the occurrence of two cases of CAR+ leukemia relapse, the first one characterized by a large expansion of CD19-/CAR+ B cells, whereas the second one showing only a minimal expansion of CAR+ leukemia cells. Moreover, in vitro and in vivo studies documented that the leukemic clone from the first patient was resistant to CAR.CD19 T-cell killing. ${ }^{5}$

Thus, we investigated whether the presence of leukemia B-cells in DPs generated from patients could correlate with the level of CD19+ leukemic cells in SM. For this purpose, $\mathrm{PB}$ mononuclear cells isolated from patients with a high percentage of circulating blasts (eg, collected at diagnosis to increase the likelihood of high levels of B-cell contamination in the SM) were genetically modified with a $\gamma$-retroviral vector carrying a second-generation CAR. CD19.41bb molecule. By applying quantitative PCR for IG rearrangements (molecular MRD), we observed B-cell contamination in $50 \%$ of the CAR T-cell products, in the absence of any statistical correlation between MRD levels in the DPs and the percentage of CD19+ leukemic cells present in the SM. In a CAR T-cell sample with detection level of B-cells below the sensitivity of the molecular assay, the EuroFlow flow cytometry platform was able to detect the presence of a significant percentage of contaminating B-cells that were also stained positive for the presence of CAR.CD19.

Moreover, time course experiments, testing the B-cell contamination in the DPs during a period of culture up to 30 days, clearly show that the level of leukemia contamination is inversely proportional to the time of the culture. Moreover, since the MRD analysis did not substantially discriminate cultures of either 
A

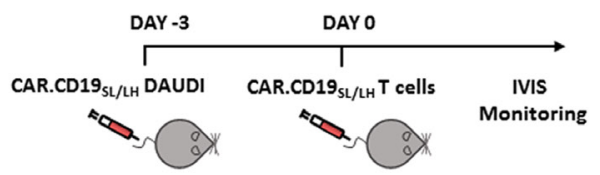

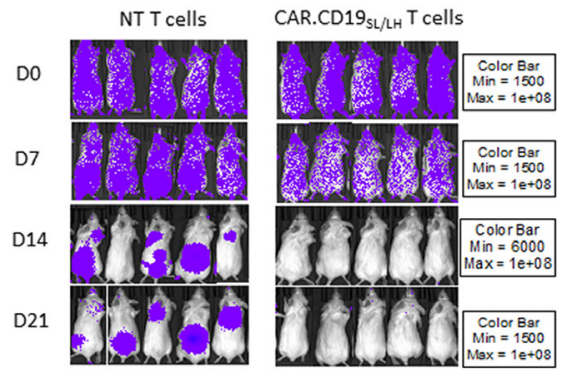

C

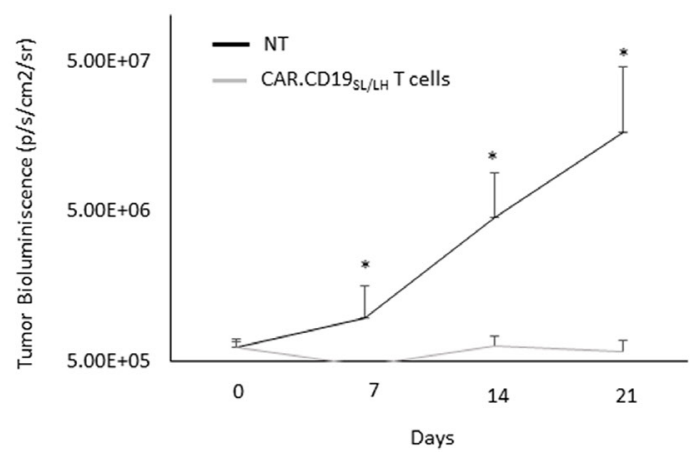

Figure 6 CAR.CD19 T-cells are able to control in vivo expansion of CAR positive lymphoma in a xenograft mouse model. (A) Schematic representation of the experimental design, with CAR.CD19 ${ }_{\text {SLLH }}$ positive/FF-Luciferase positive Daudi cells, infused at day-3. At day 0 , mice were evaluated for lymphoma engraftment and treated with $10 \times 10^{6}$ untransduced (NT) or CAR.CD19 $\mathrm{SL}$ T-cells/mouse. (B) Bioluminescence imaging of each treated mouse. (C) Mean $\pm \mathrm{SD}$ of bioluminescence values of the two mice cohorts, receiving NT (black line) or CAR.CD19 ${ }_{S \perp L L}$ T-cells (gray line). " $\mathrm{p} \leq 0.05$. CAR, chimeric antigen receptor; FF, firefly; NT, non-transduced.

untransduced or CAR+ T-cells, we could also speculate that the major factor driving B-cell disappearance in the DP is related to the inability of the B-cells to survive long term in the ex vivo culture, more than the ability of the CAR T-cells to progressively eliminate CD19+ blasts from the culture.

A more extended prospective multi-center study, including leukapheresis of patients enrolled in CAR T clinical trials would be desirable to corroborate these findings in the real-life manufacturing world. Moreover, these studies support the choice of using manufacturing processes that start from selecting CD3 positive T-cells, as well specific T-cell subtypes, to significantly reduce the number of leukemic cells in the entire production step.

CAR construct design is another factor that might affects the in vivo efficacy and safety of a CAR T-cell product. ${ }^{33}$ Some details of CAR design, including specific characteristics of the antigen-binding domain, the presence and structure of an extracellular hinge region and features of the transmembrane domain ${ }^{34}$ are critical aspects that are often underestimated. Thus, comparison of patient outcomes between trials are difficult to perform, in light of the use of DP characterized by different viral platforms, costimulatory domains, CAR design, and manufacture procedures, not to mention the disparities in clinical trial design.
For these reasons, further investigation is needed to better clarify the real relevance of all these parameters on CAR T-cell overall efficacy. ${ }^{2435}$

In this paper, we provide evidence that CAR design is a relevant factor in the case of the inadvertent CAR+ leukemiacell transduction, because it influences the ability of CAR.CD19 T-cells to recognize and kill CAR+ blasts, without modify substantially the antileukemic efficacy of CAR.CD19 T-cells.

Indeed, CAR.CD19 ${ }_{\mathrm{SL} / \mathrm{LH}}$ T-cells exert a significant antileukemia activity in both in vitro and in vivo models, at the same extent of the more conventional CAR.CD19 T-cells. Nevertheless, when the CD19 and the short-linker (SL) CAR.CD19 are expressed in cis on the same cellular membrane of leukemia B-cells, these latter showed significantly reduced CD19 MFI compared with wild-type B-cells, with CD19 being still detectable by flow cytometry, suggesting a not complete cis masking of the antigen. This finding correlates with the results of the functional analyses: low CD19 MFI expression on CAR+ leukemia cells (NALM-6, DAUDI and RAJI) was sufficient to activate CAR.CD19 T-cells. Finally, in vivo models corroborated our in vitro data. In particular, T-cells genetically modified with the clinical relevant vectors for CAR.CD19 (either with the short or long linker), show a significant in vitro control of NALM-6 leukemia. When we moved to 
evaluate the ability of CAR.CD19 T-cells to control CAR+ NALM-6 cells in the in vivo model, we observed a significant leukemia control in both cohorts of mice engrafted with short and long linker CAR+ leukemia. Nevertheless, the bioluminescence analysis showed that CAR.CD19 $9_{\mathrm{SL}}$ LH NALM-6 cells were better controlled than NALM-6 expressing long linker CAR.CD19. In a less challenging in vivo model represented by DAUDI cells infused in the NSG mice, we have also proved the complete eradication

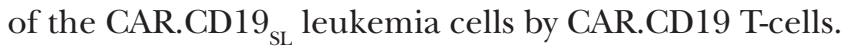

Altogether, our findings support the hypothesis that although it is feasible to proceed with the manufacturing of CAR T-cells also from patients in whom PB is contaminated by high percentage of circulating leukemia blasts, a safety concern needs to be raised relatively to the higher probability of leukemia contamination in the DPs. Selection of the effector T-cells, as well as CAR design may help increase the safety of the approach, in case of the event of B-cell blast CAR transduction occurrence.

\section{Author affiliations \\ ${ }^{1}$ Department Onco-Haematology, and Cell and Gene Therapy, Bambino Gesù Children Hospital, IRCCS, Rome, Italy \\ ${ }^{2}$ Department of Clinical Medicine and Surgery, University of Naples Federico II, Naples, Italy \\ ${ }^{3}$ Translational Program, Cancer Research Centre (IBMCC, USAL-CSIC), Institute for Biomedical Research of Salamanca (IBSAL), CIBERONC and Department of Medicine and Cytometry Service (NUCLEUS Research Support Platform), University of Salamanca (USAL), Salamanca, Spain \\ ${ }^{4}$ Centro Ricerca Tettamanti, Pediatric Department, Fondazione MBBM, University of Milan-Bicocca, Monza, Italy \\ ${ }^{5}$ Department of Bio and Health Informatics, Technical University of Denmark, Kgs. Lyngby, Denmark \\ ${ }^{6}$ Department of Pathology and Laboratory Medicine, Abramson Cancer Center, Perelman School of Medicine of the University of Pennsylvania, Philadelphia, Pennsylvania, USA \\ ${ }^{7}$ Department of Pediatrics, Sapienza University of Rome, Rome, Italy}

\section{Twitter Simona Caruso @simona.caruso and Marco Ruella @MarcoRuella}

Contributors FL and BDA are the colast authors of the paper. CQ, MG, SM and IB are cofirst authors of the paper. CQ, BDA and FL designed experimental studies, supervised the project conduction, analyzed the data and wrote the manuscript. IB, MG, SM, SDC, MS, SC, ZA, AC, BC and RC developed the in vitro models. IB, MG $\mathrm{SM}, \mathrm{BDA}$ and $\mathrm{CQ}$ performed the in vivo experiments. PM and FIM performed in silico model for the HLA peptide binding. CQ, IB, SM, MG and BDA cloned the retroviral vector. MR provided the lentiviral model and participated to data interpretation. IB, MG, SM, MS, LM-M, SG-H, MH-G, VB performed FACS analysis. AO designed FACS workflow, performed FACS data analysis and FACS data interpretation, provided expertise in flow cytometer analysis of CAR cell analysis. GC supervised the MRD analysis and molecular data interpretation. VN, SS performed MRD analysis. VB performed FACS MRD characterization on Bcp-ALL patients. LV, FDB, MA, PM and FL provided patient's samples, medical advices and expertise in pediatric lymphoma. All authors read and approve the final version of the manuscript.

Funding The experimental work was supported by grants awarded by Ricerca Finalizzata GR-2013 02359212 (CQ), GR-2016-02364546 (BDA), RF-201602364388 (FL), Accelerator Award-Cancer Research UK/AIRC/AECC-INCAR project (FL and A0), Associazione Italiana Ricerca per la Ricerca sul Cancro (AIRC)-Special Project 5×1000 no. 9962 (FL), AIRC IG 2018 id. 21724 (FL), Ricerca Corrente (FL, CQ, BDA), Ministero dell'Università e della Ricerca (Grant PRIN 2017 to FL); Italian Healthy Ministry project on CAR T RCR-2019-23669115 (coordinator FL), Independent Research grant AIFA (FL PI: 2016 call).

Competing interests None declared.

Patient consent for publication Not required.
Ethics approval Both parents and healthy donors signed a written informed consent, in accordance with rules set-up by the Institutional Review Board (IRB) of Bambino Gesù Children Hospital, IRCCS, Rome, Italy (OPBG; Approval of Ethical Committee no 969/2015 prot.no 669LB, and no 1422/2017 prot. no 810).

Provenance and peer review Not commissioned; externally peer reviewed.

Data availability statement All data relevant to the study are included in the article or uploaded as online supplemental information. More data and reagents are available on specific request and on signing of CDA, by direct contacting the corresponding author.

Supplemental material This content has been supplied by the author(s). It has not been vetted by BMJ Publishing Group Limited (BMJ) and may not have been peer-reviewed. Any opinions or recommendations discussed are solely those of the author(s) and are not endorsed by BMJ. BMJ disclaims all liability and responsibility arising from any reliance placed on the content. Where the content includes any translated material, BMJ does not warrant the accuracy and reliability of the translations (including but not limited to local regulations, clinical guidelines, terminology, drug names and drug dosages), and is not responsible for any error and/or omissions arising from translation and adaptation or otherwise.

Open access This is an open access article distributed in accordance with the Creative Commons Attribution Non Commercial (CC BY-NC 4.0) license, which permits others to distribute, remix, adapt, build upon this work non-commercially, and license their derivative works on different terms, provided the original work is properly cited, appropriate credit is given, any changes made indicated, and the use is non-commercial. See http://creativecommons.org/licenses/by-nc/4.0/.

\section{ORCID iDs}

Concetta Quintarelli http://orcid.org/0000-0002-4343-9705

Gianni Cazzaniga http://orcid.org/0000-0003-2955-4528

Marco Ruella http://orcid.org/0000-0003-4301-5811

Francesca Del Bufalo http://orcid.org/0000-0001-9643-3465

\section{REFERENCES}

1 Frey N. The what, when and how of CAR T cell therapy for all. Best Pract Res Clin Haematol 2017;30:275-81.

2 Gökbuget N. How should we treat a patient with relapsed Phnegative B-ALL and what novel approaches are being investigated? Best Pract Res Clin Haematol 2017;30:261-74.

3 Park JH, Rivière I, Gonen M, et al. Long-Term follow-up of CD19 CAR therapy in acute lymphoblastic leukemia. N Engl J Med 2018;378:449-59.

4 Maude SL, Laetsch TW, Buechner J, et al. Tisagenlecleucel in children and young adults with B-cell lymphoblastic leukemia. N Engl J Med 2018;378:439-48

5 Ruella M, Xu J, Barrett DM, et al. Induction of resistance to chimeric antigen receptor T cell therapy by transduction of a single leukemic $B$ cell. Nat Med 2018:24:1499-503.

6 Ruella M, Barrett DM, Shestova O, et al. A cellular antidote to specifically deplete anti-CD19 chimeric antigen receptor-positive cells. Blood 2020;135:505-9.

7 Quintarelli C, Sivori S, Caruso S, et al. Efficacy of third-party chimeric antigen receptor modified peripheral blood natural killer cells for adoptive cell therapy of B-cell precursor acute lymphoblastic leukemia. Leukemia 2020;34:1102-15.

8 Kalina T, Flores-Montero J, van der Velden VHJ, et al. EuroFlow standardization of flow cytometer instrument settings and immunophenotyping protocols. Leukemia 2012;26:1986-2010.

9 van Dongen JJM, van der Velden VHJ, Brüggemann M, et al. Minimal residual disease diagnostics in acute lymphoblastic leukemia: need for sensitive, fast, and standardized technologies. Blood 2015;125:3996-4009.

10 Theunissen P, Mejstrikova E, Sedek L, et al. Standardized flow cytometry for highly sensitive MRD measurements in B-cell acute lymphoblastic leukemia. Blood 2017;129:347-57.

11 Sędek Łukasz, Theunissen P, Sobral da Costa E, et al. Differential expression of CD73, CD86 and CD304 in normal vs. leukemic Bcell precursors and their utility as stable minimal residual disease markers in childhood B-cell precursor acute lymphoblastic leukemia. $J$ Immunol Methods 2019;475:112429.

12 Di Stasi A, De Angelis B, Savoldo B. Gene therapy to improve migration of $\mathrm{T}$ cells to the tumor site. Methods Mol Biol 2010;651:103-18.

13 Orlando D, Miele E, De Angelis B, et al. Adoptive immunotherapy using PRAME-Specific T cells in medulloblastoma. Cancer Res 2018;78:3337-49. 
14 Leung W-H, Gay J, Martin U, et al. Sensitive and adaptable pharmacological control of CAR T cells through extracellular receptor dimerization. JCI Insight 2019;4.

15 An N, Tao Z, Li S, et al. Construction of a new anti-CD19 chimeric antigen receptor and the anti-leukemia function study of the transduced T cells. Oncotarget 2016;7:10638-49.

16 Castella M, Boronat A, Martín-lbáñez R, et al. Development of a novel anti-CD19 chimeric antigen receptor: a paradigm for an affordable CAR T cell production at academic institutions. Mol Ther Methods Clin Dev 2019;12:134-44.

17 Kang CH, Kim Y, Lee HK, et al. Identification of potent CD19 scFv for CAR T cells through scFv screening with NK/T-cell line. Int J Mol Sci 2020;21:9163.

18 Ninomiya S, Narala N, Huye L, et al. Tumor indoleamine 2,3-dioxygenase (IDO) inhibits CD19-CAR T cells and is downregulated by lymphodepleting drugs. Blood 2015;125:3905-16.

19 van Dongen JJM, Orfao A, EuroFlow Consortium. EuroFlow: resetting leukemia and lymphoma immunophenotyping. basis for companion diagnostics and personalized medicine. Leukemia 2012;26:1899-907.

20 Kalos M, Levine BL, Porter DL, et al. T cells with chimeric antigen receptors have potent antitumor effects and can establish memory in patients with advanced leukemia. Sci Transl Med 2011;3:ra73.

21 Maude SL, Frey N, Shaw PA, et al. Chimeric antigen receptor T cells for sustained remissions in leukemia. $N$ Engl J Med 2014;371:1507-17.

22 Lee DW, Kochenderfer JN, Stetler-Stevenson M, et al. T cells expressing CD19 chimeric antigen receptors for acute lymphoblastic leukaemia in children and young adults: a phase 1 dose-escalation trial. Lancet 2015;385:517-28

23 Gardner RA, Finney O, Annesley C, et al. Intent-To-Treat leukemia remission by CD19 CAR T cells of defined formulation and dose in children and young adults. Blood 2017;129:3322-31.

24 Shah NN, Fry TJ. Mechanisms of resistance to CAR T cell therapy. Nat Rev Clin Oncol 2019;16:372-85.
25 Fry TJ, Shah NN, Orentas RJ, et al. CD22-targeted CAR T cells induce remission in B-ALL that is naive or resistant to CD19-targeted CAR immunotherapy. Nat Med 2018;24:20-8.

26 Jacoby E, Nguyen SM, Fountaine TJ, et al. CD19 CAR immune pressure induces B-precursor acute lymphoblastic leukaemia lineage switch exposing inherent leukaemic plasticity. Nat Commun 2016;7:12320.

27 Kenderian SS, Porter DL, Gill S. Chimeric antigen receptor T cells and hematopoietic cell transplantation: how not to put the cart before the horse. Biol Blood Marrow Transplant 2017;23:235-46.

28 Mueller KT, Maude SL, Porter DL, et al. Cellular kinetics of CTL019 in relapsed/refractory B-cell acute lymphoblastic leukemia and chronic lymphocytic leukemia. Blood 2017;130:2317-25.

29 Künkele A, Johnson AJ, Rolczynski LS, et al. Functional tuning of cars reveals signaling threshold above which CD8+ CTL antitumor potency is attenuated due to cell Fas-FasL-Dependent AICD. Cancer Immunol Res 2015;3:368-79.

30 Gargett T, Yu W, Dotti G, et al. GD2-specific CAR T cells undergo potent activation and deletion following antigen encounter but can be protected from activation-induced cell death by PD-1 blockade. Mol Ther 2016;24:1135-49.

31 Stroncek DF, Lee DW, Ren J, et al. Elutriated lymphocytes for manufacturing chimeric antigen receptor T cells. J Transl Med 2017;15:59.

32 Ceppi F, Rivers J, Annesley C, et al. Lymphocyte apheresis for chimeric antigen receptor T-cell manufacturing in children and young adults with leukemia and neuroblastoma. Transfusion 2018;58:1414-20.

33 Kawalekar OU, O'Connor RS, Fraietta JA, et al. Distinct signaling of coreceptors regulates specific metabolism pathways and impacts memory development in car T cells. Immunity 2016;44:380-90.

34 Alabanza L, Pegues M, Geldres C, et al. Function of novel anti-CD19 chimeric antigen receptors with human variable regions is affected by hinge and transmembrane domains. Mol Ther 2017;25:2452-65.

35 Brudno JN, Kochenderfer JN. Chimeric antigen receptor T-cell therapies for lymphoma. Nat Rev Clin Oncol 2018;15:31-46. 